\title{
A Review on the Relevant Applications of Machine Learning in Agriculture
}

\author{
Noran S. Ouf \\ Electronics Research Institute, National Research Center, El-Tahrir Street, Dokki, Giza, Egypt ${ }^{3}$
}

\begin{abstract}
Manual identification, classification and taxonomy of a definite and specific species or plant disease are generally obstructed by several difficulties such as time consumption, the limited number of expert specialists and the increase in the number of the defined characteristics of each species. The steady progress of the computational technology over the last few years concerning the automated species recognition including plant structures is be easier particularly in the presence of huge databases of information and the enhancement of classification and analyzing image technology. Several investigators are currently working in agriculture field mainly those concerned with plant identification or of plant disease recognition through image processing, extraction of identical features and classifying them into exact classes. In this review, the integration of computer science with agriculture has been discussed to detect, quantify, predict, early identify and classify plant diseases as well as forecasting agricultural crops using different machine learning techniques. Weather forecasting, smart irrigation system, plant leaf identification, etc will also discussed. The aim of this paper is to provide the investigators particularly biologists with computational recognition techniques as well as the possibility of using image informative morphological features of a species or a group of related species in recognition of many biological organisms including plants and microorganisms.
\end{abstract}

Keywords: Artificial Intelligence, Agriculture, Image Processing, Recognition

\section{INTRODUCTION}

Machine Learning (ML) is a division of artificial intelligence in the field of computer science that lets software applications to be more truthful in prediction of the outcomes without being explicitly programmed. The basic principle of ML is to construct algorithms that can receive input data and use statistical techniques to predict an output while updating outputs as new data becomes available. The name ML was formulated by Samuel Arthur (1988) [1]. In addition to investigating the recognition pattern and artificial intelligence, ML expands to investigation of the construction of algorithms that can learn from and make predictions on data. ML is employed with good performance in a variety of computational tasks such as programming, building models and designing including as examples email filtering, detection of network intruders or malicious insiders working towards a data breach (Dickson, 2017) [2] optical character recognition (Wernick, 2010) [3] learning to rank, and computer vision. ML is firmly identified with (and frequently covers with) computational insights, which additionally centers around forecast making using computer. It has solid connections to scientific enhancement, which conveys strategies, hypothesis and application areas to the field. ML is now and probably conflated with information mining (Mannila, 1996) [4] where the subfield concentrates more on exploratory information investigation and is known as unsupervised learning (Bishop, 2006) [5]. Machine learning can likewise be unsupervised and be utilized to learn and build up pattern conduct profiles for different elements and afterward used to find important irregularities. Within the field of information investigation, ML is a technique used to devise complex models and calculations that loan themselves to forecast; in commercial use, this is known as predictive investigation. These explanatory models permit specialists, data researchers, designers, and experts to "create dependable, repeatable choices and results" and reveal "concealed insights" through gaining from chronicled connections and data pattern. Over the last few years, several models and methods of automated classification systems of specimens` images have been considered. The accuracy of automated recognition systems for biological images is greatly dependent on the quantity and quality of learned images. The images are firstly processed using various preprocessing techniques to extract relevant features that can be employed for classification. Feature extraction techniques are useful in image processing applications and feature selection is critical to the whole identification process as the poorly attained features probably result in poor recognition (Kumar and Bhatia, 2014) [6] . This review describes a general overview of the different techniques and methods that have been employed in automated identification for biological species and summarizes the previous technologies that have been significantly applied in some fields of agriculture.

A. Crop Disease Prediction And Early Identification: The traditional approaches for disease detection requires continues monitoring and observation of farms either by farmers or by experts although, it is very costly and time 
International Journal of Innovative Research in Electrical, Electronics, Instrumentation and Control Engineering

Vol. 6, Issue 8, August 2018

consuming. In last few years, various researchers have focused into this area to provide optimized solution. Popular methods have utilized ML, image processing and classification based approaches to identify and detect the diseases on agricultural products.

The techniques for disease detection have utilized various image processing methods followed by various classification techniques. Identifying disease from the images of the plant is one of the interesting research areas in computer and in agriculture field. ML methods have been discussed by several investigators to detect, quantify and classify plant diseases (Al-Hiary et al, 2011 [7], Wang et al, 2012[8], Barbedo, 2013[9], Khirade and Patil, 2015[10], Singh and Misra, 2017[11]). Disease detection includes rice disease identification using pattern recognition techniques, pattern discrimination models, extraction of rice leaf disease image based on back-propagation neural network and application of support vector machine for detection of rice diseases using shape and color texture features (Phadikar and Sil, 2008 [12], Liu and Zhou, 2009 [13], Yao et al. 2009[14]), image processing techniques for diagnosis of paddy diseases (Kurniawati et al. 2009 [15], Anthonys and Wickramarachchi, 2009[16], Majid et al. 2013[17], Kahar et al. 2015 [18], Suman and Dhruvakumar, 2015 [19]), ANN for recognition of flower diseases (Tigistu and Assabie, 2015 [20]). The distinctive strategies shoed higher exactness contrasted with the conventional traditional techniques like regression investigation. These techniques are concerned with noisy and multi-faceted information (Suraksha et al. (S. I. S. S. B) 2016 [21], Donatelli et al. 2017[22], Evert et al. 2017[23]). Early crop infection recognition and order has been finished utilizing SVM (Ruß et al. 2008 [24]). SVM technique was implemented for sugar beet diseases and offered in the report published by Rumpf et al. (2010)[25], where the classification accuracy was between 65 and $90 \%$, depending on the type and stage of disease. Likewise, Zhou and Chen earlier in 2002 [26] indicated methods that combine the feature extraction and neural network ensemble (NNE) for plant disease recognition. Through training a definite number of neural networks and combining their results after that, NNE offers a better generalization of learning ability. Such method was implemented only for recognizing tea leaf diseases with final testing accuracy of 91\% (Chandrakarmokar et al. 2015) [27].

An alternative method based on leaf images and using artificial neural networks (ANNs) as a technique for an automatic recognition and classification of plant diseases was used in conjunction with -means as a clustering procedure proposed by Al-Hiary et al (2011) [7]. ANN consisted of 10 hidden layers. The number of outputs was 6 which was the number of classes representing five diseases along with the case of a healthy leaf. On average, the accuracy of classification using this approach was 94.67\%. Several authors (Lenz et al., 2015 [28], Alipanahi et al. 2015 [29], Arevalo et al. 2015 [30], Zhang et al. 2016 [31]) employed the deep learning methods for solving most complex tasks in different areas of research in biology, bioinformatics, biomedicine, robotics, and 3D technologies.

There are a few elements like soil quality, crop cycle, seed quality which can prompt weakness and diseases in crops. Machine learning calculations viably think about all the conceivable components, memorable information and in addition satellite/sensor information of fields to give significant infection classifiers. Disease location utilizing pictures of harvest leaves has been executed utilizing pattern regonition branch of ML. It works by getting designs from input information and isolating them into classes of ailments (Wolfert, 2017) [32].

The early and exact visual diagnosis of plant disease is very important although it is not enough and probably the process exposed to some human error. More accurete diagnosis and disease recognition by a trained computer After sorting through hundreds of thousands of images of infected plants, a ML algorithm can spot disease type, severity, and in the future, may even recommend management practices to control and manage plant diseases. ML in agriculture allows for more accurate disease diagnosis and help in elimination of the wasted energy and resources from misdiagnoses. Farmers can upload field images taken by satellites, UAVs, land based rovers, pictures from smartphones, and use this software to diagnose and develop a management plan (Khirade and Patil, 2015) [10], Fig. 1. The image processing methods are connected to the attained images to extricate helpful highlights that are essential for image examination. Dhaygude and Kumbhar (2013) [33] indicated that there are mainly four steps in developed processing scheme which are RGB (red, green and blue), image acquisition, transformation of the input image from RGB to Hue, Saturation, and Value (HSV) format, masking and removal of the green-pixels by using pre-computed threshold level which is useful for segment extraction. HSV model is an ideal tool for color perception (Siddiqi et al. 2009) [34]. Ananthi and Varthini (2012) [35] indicated that the color transformation structure into Hue saturation intensity (HSI) shading space portrayal is used to facilitate the particular of colors in some standard, by and large approved way. HSI color model is a mainstream color model since it depends on human recognition (Gonzalez and Woods, 2002) [36]. Hue is a color attribute that indicates to the prevailing color as seen by a spectator. Saturation denotes to the relative purity and abundance of white light. Color spaces can be easily changed from one space to another. After the change in procedure, the Hue component is considered for further examination (Fig. 2). S and I are dropped since they doesn't give extra data. Fig. 2 demonstrates the H, S and I components. 


\section{International Journal of Innovative Research in Electrical, Electronics, Instrumentation and Control Engineering}

Vol. 6, Issue 8, August 2018

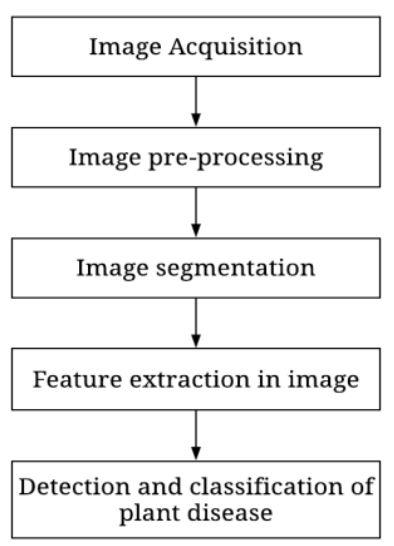

Figure1. Basic steps for plant disease detection and classification (Khirade and Patil, 2015) [10]

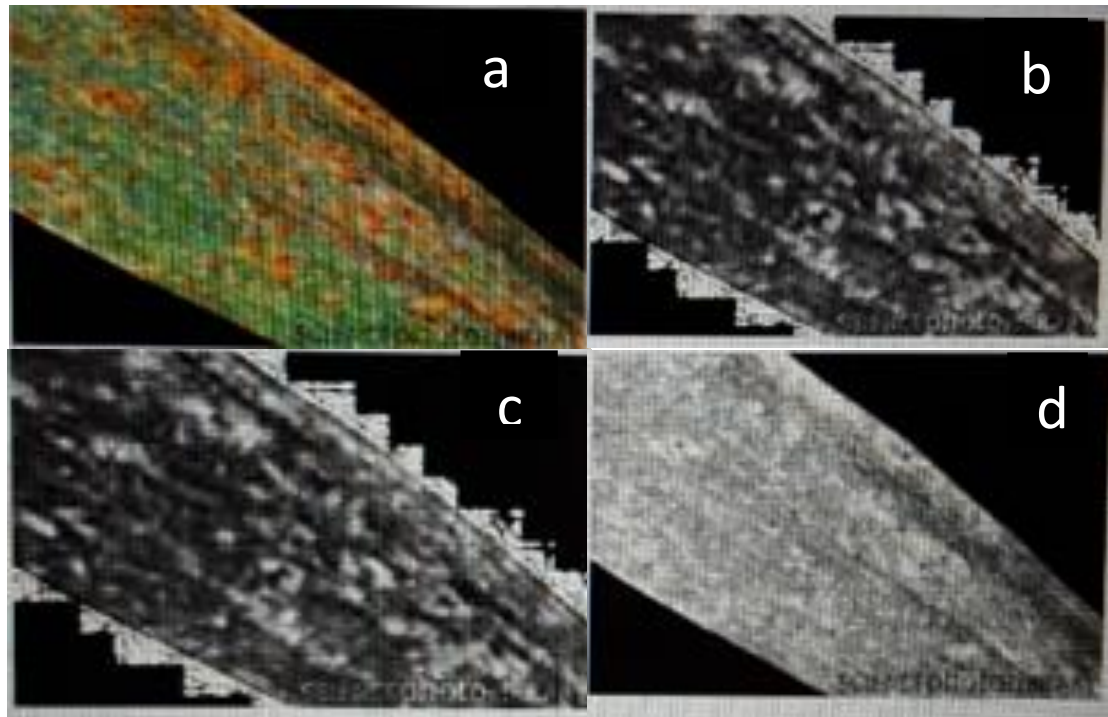

Figure2. a) Input image infected by fungus b) Hue Component c) Saturation Component

d) Value component (Dhaygude and Kumbhar, 2013) [33]

The last primary step is the segmentation where the contaminated area is then sectioned into various patches of equivalent size. It has been shown that not all fragments contain critical measure of data, but, the patches which are having in excess of $50 \%$ of the data are considered for the further investigation. Singh and Misra (2017) [37] stated that the first step of fitness computation the dataset of pixel is clustered according to nearest respective cluster centers such that each pixel $\mathrm{x}_{\mathrm{i}}$ of color image is put into the respective cluster with cluster center $\mathrm{z}_{\mathrm{j}}$ for $\mathrm{j}=1,2, \ldots, \mathrm{K}$ by the following equations:

$$
\begin{aligned}
& \text { If }\left\|x_{i}-z_{j}\right\|<\left\|x_{i}-z_{l}\right\|, \\
& i=1,2, \ldots, m \times n, \quad l=1,2, \ldots, k, \quad \text { and } p \neq j .
\end{aligned}
$$

The calculating of the mean of each pixel of the assigned clusters is the next step of new cluster centers. The new center of cluster $\mathrm{Zi}$ is given by for the cluster $\mathrm{Ci}$ as:

$$
\mathrm{Z}_{i}(r, g, b)=\frac{1}{n_{i}} \sum_{x_{j} \in c_{i}}\left(x_{j}(r, g, b)\right) \quad i=1,2, \ldots k
$$

Now the fitness function is computed by calculating Euclidean distance between the pixels and their respective cluster by using following equations 


$$
\begin{aligned}
& M=\sum M_{i} \\
& M_{i}=\sum_{x_{j} \in c_{i}}\left|\left(x_{j}(r, g, b)-z_{i}(r, g, b)\right)\right|
\end{aligned}
$$

For feature extraction the applied technique is color co-occurrence method. It is the methodology in which both the texture and color of an image are utilized, to come to the distinctive features, which reveals that image. The color coevent surface examination strategy is created through the spatial gray-level dependence matrices (SGDM). SGDM is a measurable method to illustrate shape by statistically testing the manner in which certain grey levels happen in connection to other grey levels (Argenti et al. 1990) [38]. These frames measure the prospect that a pixel at one specific dark level will happen at a distinctive distance and introduction from any pixel given that pixel has a second specific grey level. There are three major mathematical processes in the color co-occurrence method. First, conversion of the RGB images of leaves is done into HIS color space representation. After completion of this process, a color cooccurrence matrix is generated. Each pixel map, which results into three color co-occurrence matrices, one for each of H, S, I. is used. Features entitled are texture features, which include confined homogeneity, contrast, cluster shade, energy, and cluster distinction. These features are computed for the $\mathrm{H}$ image as given in equations (5)-(8).

$$
\begin{aligned}
& \text { CONTRAST }=\sum_{i, j=0}^{N-1}(i, j)^{2} C(i, j) \\
& \text { Energy }=\sum_{i, j=0}^{N-1} C(i . j)^{2} \\
& \text { Local Homogeneity }=\sum_{I, j=0}^{N-1} C(i, j) /\left(1+(i-j)^{2}\right) \\
& \text { Entropy }=-\sum_{i, j=0}^{N-1} C(i . j) \log C(i . j)
\end{aligned}
$$

Tripathi and Maktedar (2016) [39] reported diagrammatic detection for citrus leaf disease during the International Conference on Computing Communication Control and automation (ICCUBEA) (Fig. 3)

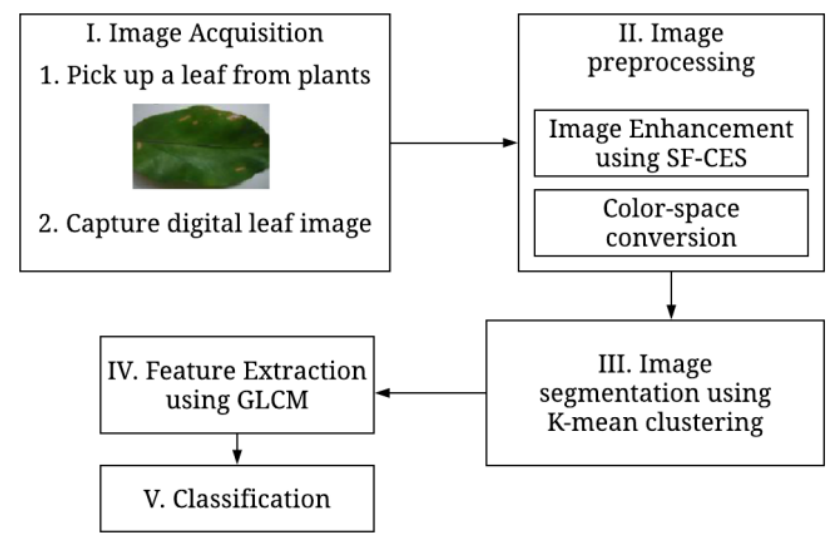

Figure 3. Disease detection on citrus leaf (Tripathi and Maktedar 2016) [39]

Ferentinos (2018)[40] created convolutional neural system models to perform plant disease location and analysis utilizing simple leaves pictures of infected and healthy plants, through profound learning procedures. Preparing of the models was performed with the utilization of an open database of 87,848 pictures, containing 25 unique plants in an arrangement of 58 definite classes of including vigorous plants. A few model designs were prepared, with the best accomplishment attaining a $99.53 \%$ achievement rate in distinguishing the relating (plant, disease) mix (or vigorous plant). The altogether high achievement rate makes the model an extremely helpful warning or early cautioning device, and an approach that could be additionally extended to help a coordinated plant disease recognizable proof framework to work in genuine development conditions. Shen (2018) [41] built up a discovery and distinguishing proof strategy for put away grains in storage infected with insects by applying profound neural system. Adults of six species of common 
International Journal of Innovative Research in Electrical, Electronics, Instrumentation and Control Engineering

\author{
Vol. 6, Issue 8, August 2018
}

insects mixed with grain and dockage were artificially added into the developed insect-trapping device. Database of RGB images of these live insects was built up. Faster region-based convolutional neural network (R-CNN), is performed to extract areas which might contain the insects in these images and classification of the insects in these areas were achieved. An improved inception network was established to extract feature maps. The last strategy accomplish great outcome for recognition and classification of insects. The test results showed that the developed method accurately revealed excellent results in discovery and documentation of grains infected with under storage.

Pukkela and Borra (2017) [42] recently designed technological methods for the identification of plants and detection of their diseases in order to meet the new challenges facing farmers and their learning needs. They deliver an overview of various methods and techniques for feature extraction, segmentation and the classification of patterns of captured leaves in order to identify plant leaf diseases and their severity. As well, the authors analyzes various automatic grading systems and parameters used in estimating the severity of different plant diseases and discussed a variety of plant diseases. They discussed the use of a radial basis function (RBF) kernel-based support vector machine (SVM) learning algorithm for the detection of these diseases, which include different plant diseases. The work of these authors also deals with the assessment of severity of foliar diseases found in soybean plants (using segmentation), rice blast disease (using SVM) and single disease severity level of plasmopara viticola in grape leaves (using a k-means clustering algorithm). The existing gaps in the technology for precision agriculture are discussed, and the requirements and demands to be met by agriculturists are presented. Akhtar et al. (2013) [43] indicated that automatic identification and classification of plant diseases can be supportive to agriculture yield maximization. They compare performance of several ML techniques for identifying and classifying foliar plant disease patterns from images. They stated that a three-phase framework has been implemented for this purpose. First, image segmentation is performed to identify the diseased regions. Then, features are extracted from segmented regions using standard feature extraction techniques (Singh and Misra, 2017) [37] (Fig. 4). These features are then used for classification into disease type. Experimental results indicated that the proposed technique is significantly better than the other techniques used for plant disease identification and SVM outperforms other techniques for classification of diseases.

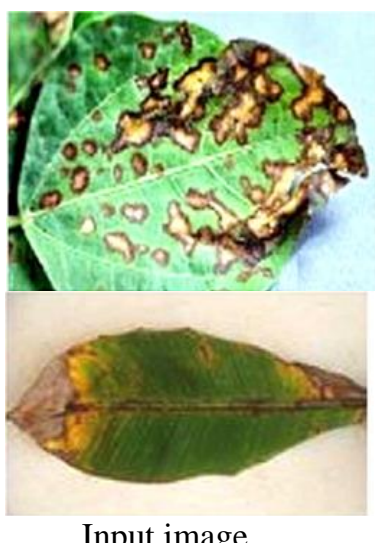

Input image

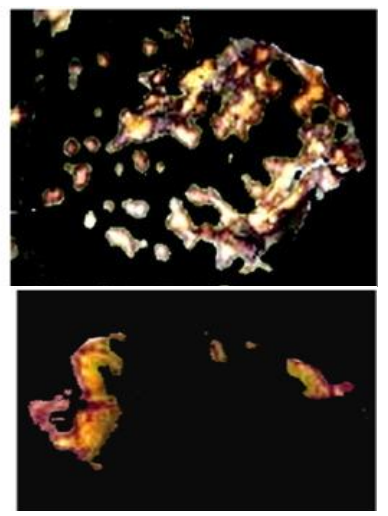

segmented image

Fig. 4. Input and output images of bacterial plant diseases (Singh and Misra, 2017)[37]

Artificial Neural Network (ANN) techniques was implemented in recognition of the colour change due to the drastic discoloration of the rubber leaf as result of white root disease infection. The early detection of rubber tree white-root disease based on leaf discoloration is important in order to make a decision. Sulaiman et al. (2014) [44] were able to measure the percentage of green colour in rubber leafs using ZEISS Spectrometer which is an instrument operated based on application optical sensor system and wavelength of the green color (495-570nm) which was used as color reference. The instrument was used to measure properties of light over a specific portion of the electromagnetic spectrum to identify materials. This instrument interfaces with a software to extract spectrum after the process was done by the instrument. The performance of the optimized model was decided after observing the receiver operating curve (ROC) plot analysis. The overall percentage accuracy for the optimized model is found to be $84.4 \%$ while the sensitivity for healthy, medium and worst cases are $83.3 \%, 73.3 \%$ and $96.7 \%$ respectively. Vanathi et al. (2017) [45] used image processing techniques to capture digital image by camera and applied the images to ostu's and k-means algorithms. In ostu's method, automatically performs thresholding or the reduction of a gray level image to a binary image is performed, while in k-means algorithms, the image is partitioned into K clusters and the pixels are randomly assigned to the clusters resulting in clusters that have roughly the same number of data points. The same investigatirs showed that segmentation of image by ostu's gives less accuracy than k-means and the authors were performed the classification of diseases using SVM. Bashir and Sharma (2012) [46] stated that it is possible to detect remote area 
International Journal of Innovative Research in Electrical, Electronics, Instrumentation and Control Engineering

Vol. 6, Issue 8, August 2018

plant disease detection using image processing by combination of K-means clustering and texture analysis. The algorithm being used for texture analysis is co-occurrence method. K-means clustering has been used for texture analysis.

B. Crop Yield Prediction: Agriculture planning plays an important role in economic growth and food security of agro-based country. The choice of the reasonable crop that will be planted assumes an imperative part in amplification of the development and yield (Frausto-Solis et al., 2009) [47]. Crop yield prediction is difficult because it depends on many interrelated factors like soil structure and its composition, weather forecasts, seasonal rains, environment climate, geography of the region, marketing and prices etc (Liu et al., 2001 [48], Ruß 2009 [49]). In addition, farmer decisions such as applied irrigations, pest pathogens and fertilizers applications, crop rotation should be considered. Crop yield prediction is a major problem in agriculture.

Machine learning means to give the knowledge to the machine. Machine learning is fundamental approach for accomplishing a powerful answer for several complex agricultural issues and gives numerous viable calculations which can distinguish the input and yield relationship as well as yield forecast and prediction and selection. Ghosh and Koley (2014) [50] trained Back Propagation Networks(BPN) with reference crops' growth properties available nutrient status and its ability to provide nutrients out of its own reserves and through external applications for crop production in both cases, BPN was able to find and suggest the correct correlation percentage among those properties. The performance of the Back Propagation Neural network model was evaluated using a test data set and their results showed that artificial neural network with certain number of neurons in hidden layer had better performance in predicting soil properties than multivariate regression.

According to Mishra et al. (2016) [51], there are various types of ML techniques such as supervised and unsupervised learning. Supervised learning means there is one supervisor to supervise the thing that is the program is trained by training examples and then that can be used to find the accurate conclusion for new data. Artificial neural network, Bayesian network, decision tree, support vector machines, ID3, k-nearest neighbor, hidden markov model etc. are some of the examples of supervised learning. The unsupervised machine learning means a vast amount of data is given to the program and the program will find the patterns and the relations between them. So hidden patterns in the data can be discovered using unsupervised learning Some examples of unsupervised learning algorithms are k-nearest neighbor, self-organizing map, and partial based clustering, hierarchical clustering, k-means clustering etc.

Procedures like Artificial neural systems, K-closest neighbors and decision trees have huge parts in the setting of crop determination which depends on different elements. Crop choice in view of the impact of regular disasters like starvations has been performed by Okori and Obua (2011) [52] in view of ML. The utilization of ANN to pick the crop in light of soil and environmental weather has been appeared by specialists (Snehal, and Sandeep, 2014) [53]. A plant supplement administration framework has been proposed in view of ML strategies to address and manage the issues of soil and keep up its fertility levels and thus enhance the product yield (Ghosh and Koley, 2010) [50]. A crop choice technique called CSM has been proposed (Kumar et al. 2015) [54] which helps in crop determination in light of its yield forecast and different environmental variables. The method depends on various parameters such as production rate, market price and government policies. Many researchers studied prediction of yield rate of crop, prediction of weather, soil classification and crop classification for agriculture planning using statistics methods or ML techniques. If there is more than one option to plant a crop at a time using limited land resource, then selection of crop is a puzzle. CSM is also employed to solve crop selection problem, and maximize net yield rate of crop over season and subsequently achieves maximum economic growth of the country. The proposed method may improve net yield rate of crops.

Shastry et al. (2016) [55] contrasted two recognized prediction systems to expect wheat yield which are artificial neural Networks (ANN) and Multiple Linear Regression (MLR). The researchers considered a several parameters like precipitation amount, crop biomass, soil evaporation, transpiration, extractable soil water (ESW) and fertilizer added (NO3). They demonstrated that the customized artificial neural networks (C-ANN) display performs better with a higher R2 measurement and a lower rate forecast error than the MLR and Default-artificial neural networks (D-ANN) models on the test dataset (Fig. 5). Another strategy for quick and non-damaging assessment of the general assimilation capacity of plants with the use of leaf spectral reflectance was recently suggested by some workers (Serbin et al., 2012 [56]; Ainsworth et al., 2014 [57]; Yendrek et al., 2017 [58]). The reflectance spectrum ranging from the visible over the near infrared to the intermediate infrared $(350$ to $2500 \mathrm{~nm}$ ) gives data on the physical and chemical state as well as surface and texture properties of the material under survey. Reflectance spectra from crop canopies helped in the assessment of the plants' composition, nutritional status, as well as certain stress parameters. This includes estimates of nutrient components and macronutrient concentration (Gillon et al., 1999 [59]; Zhai et al., 2013 [60]), water content and water use efficiency (Wang et al., 2012a, 2012b) [61, 62], chlorophyll content (Atzberger et al., 2010)[63], cell 
International Journal of Innovative Research in Electrical, Electronics, Instrumentation and Control Engineering

Vol. 6, Issue 8, August 2018

wall composition (Penning et al., 2009) [64], content of secondary metabolites (Couture et al., 2013 [65]; Jia et al., 2013 [66]), heavy metal content (Liu et al., 2010) [67], disease expansion (Xu et al., 2006 [68]; Mahlein et al., 2012 [69), and species structure (Borregaard et al., 2000 [70]; Manevski et al., 2011[71]). Heckmann et al (2017) [72] demonstrated that the leaf reflectance phenotyping is proficient technique for enhancing crop photosynthetic limit.

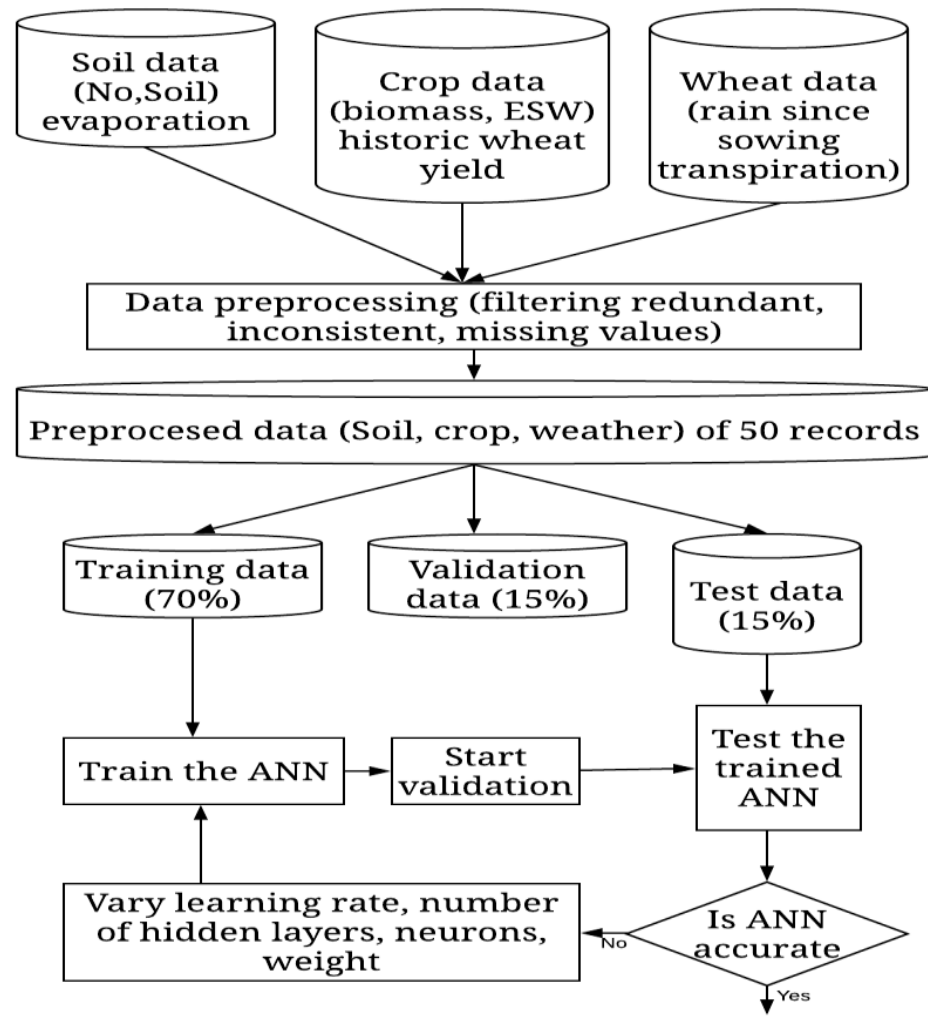

Predicted yeild

Figure5. Customized Artificial Neural Networks (C-ANN) model for wheat yield prediction (Shastry et al 2016) [55]

C. Weather Forecasting: The integration of computer science with agriculture helps in forecasting agricultural crops. Few evaluations have been conducted to determine the impact of including weather forecasts, as opposed to using historical weather data (commonly used) in crop models. In literature, several published papers showed that the most important effective meteorological factors on crop yield, was quantity and quality of rainfall, but the most sensitivity stages relative to rainfall are flowering and heading. Therefore, it is required to build on objective methodology for preharvest crop forecasting. Building up a suitable model will have certain merits over the traditional forecasting method. Historically, several important fusion of machine learning techniques in agriculture started in 1979 uptill now and include Nonlinear Regression (House, 1979) [73] for Forecasting Corn Yields, Markov Chain Approach (Matis et al. 1989) [74], Linear Regression (Shibayama, 1991) [75] for Estimating Grain Yield of Maturing Rice, Belief Networks (Yiqun et al. 1994) [76] for Future Crop Production, Neuro-Fuzzy Modeling (Stathakis et al. 2006) [77]for Crop Yield Prediction, Secpnd Order Markov Chains (Jain et al. 1998) [78] for Forecasting of Crop Yields, Polynomial Regression (Wilcox, 2000) [79] for Factors Affecting the Yield of Winter Cereals in CropMargins, Deterministic and Probabilistic Prediction Approaches (Oludhe and Christopher, 2002)[80] for Season to Inter-annual Climate Forecasting, FINkNN: a fuzzy interval number k-nearest neighbour classifier (Petridis et al. 2003)[81] for prediction of sugar production from populations of samples, Logistic regression model (LRM) (Paul et al. 2004) [82], multivariate linear regression (MLR) (Jiang et al. 2004 [83], Kaul et al. 2005[84]) for crop yield prediction, Artificial neural networks (Monisha et al. 2005)[85] for corn and soybean yield prediction, Neural Network (Chen and Mcnairn, 2006) [86] for Rice Crop Monitoring, Artificial Neural Networks (Shabri et al, 2009)[87] for Forecasting Rice Export, Building a fuzzy logic information network and a decision-support system (Gorni and Augusto, 2008)[88] for olive cultivation in Andalusia, Regression (Priya and Suresh, 2009)[89] for sugarcane yield using climatic variables, Decision Tree Algorithms (Veenadhari et al. 2011)[90] for Soybean Productivity Modelling, A Fuzzy Modelling of Decision Support System (Salleh 2012)[91] for Crop Selection, Time Series Techniques (Hong-Ying et al. 2012)[92] for Crop Yield Forecast, Data mining with climate variable (Kumar and Kanth, 2013)[93] for Jowar Crop Yield in India, Fuzzy Cognitive Map learning approach (Papageorgiou et al. 2013)[94] for Yield prediction in apples, 
International Journal of Innovative Research in Electrical, Electronics, Instrumentation and Control Engineering

Vol. 6, Issue 8, August 2018

Regression and Neural Networks Models (Prasad and Begum 2013)[95] for Prediction of Crop Production, K-means and Appriori algorithm (Fathima, 2014)[96] for Crop type and Irrigation parameters, Modified K-Means Clustering (Utkarsha et al. 2014)[97] for Crop Prediction, Artificial Neural Network Approach (Dahikar and Rode, 2014)[98] for Agricultural Crop Yield Prediction, Markov logic model (Osman et al. 2015)[99] for Crop rotations for early crop mapping, Naïve Bayes, J48, random forests, support vector machines, artificial neural networks (Sujatha , 2016)[100] for prediction of Climate data and Crop parameters for crop yield, Naïve Bayes and Apriori algorithm (Hemageethaa, 2016)[101] for yield Prediction and various soil parameters like pH, Nitrogen, moisture etc, Regression Analysis (RA) and Linear Regression (LR) (Sellam and Poovammal, 2016)[102] for various environmental factors that influence the crop yield and the relationship among these parameters, Numerical weather prediction model such as MM5 model (Giannaros, 2017)[103] for Evaluation of numerical weather prediction model, namely the Weather Research and Forecasting (WRF), with respect to the simulation of wind.

On the other hand, crop yield differs spatially and temporally with a non-linear behavior (Liu et al., 2001[48]; Drummond et al., 2003[104]; Schlenker \& Roberts, 2006[105]), introducing large deviations from one year to another. Thus, more efficient methods have been developed, which can be classified as crop growth models and data driven models. Crop models perform an abstraction of the dynamic mechanistic of the plant's physiological stages by fitting them into a mathematical model (Safa et al., 2004)[106]. Most of the mechanistic models are crop specific: SOYGRO for legumes (Wilkerson et al., 1983)[107]; AFRCWHEAT2 (Porter, 1993)[108] and Sirius (Jamieson et al., 1998)[109] for wheat; CERES-Maize (Jones \& Kiniry, 1986)[110] for corn. Some others, such as SUCROS (Spitters et al., 1988)[111], SUCROS2 (Goudriaan \& van Laar, 1994)[112] and STICS (Brisson et al., 1998)[113] are available for various crop types through parameter fitting. An evaluation performed by Jamieson et al. (1998)[109] for the wheat crop shows that some of these models has a reasonable accuracy, with deviations within 10\%. Regrettably, as reported by Varcoe (1990)[114] and Drummond et al. (2003)[104], this kind of models is expensive in terms of time and money, being impractical for massive application and agricultural planning. The Autoregressive Conditional Heteroskedasticity (ARCH) model introduced by Engle (1982)[115] explicitly recognizes the difference between the unconditional and the conditional variance allowing the latter to change over time as a function of past errors. The statistical properties of this new parametric class of models has been studied further in Weiss (1982)[116]. Two years later, Bollerslev introduced the Generalized Autoregressive Conditional Heteroskedasticity (GARCH) model to allow for past conditional variances in the current conditional variance equation for analysis of the variability. In the ARCH model, variability of rainfall stations exceeding a normal condition, are computed in a specified long-period. The ARCH model can be denominated based on the effects variance of the error term of an actual series. The ARCH family include ARCH, GARCH, ARCH in Mean (ARCH-M), Exponential GARCH (EGARCH), Glosten, Jagannathan and Runkle (GJR) and Threshold Autoregressive Conditional Heteroskedasticity (TARCH). The favorable choice of ARCH family models are the spatial distributions in the characters and designs of rainfall, but these also can be nonlinear as they can response in very different rainfall variability (Javari, 2016)[117] among stations (Gouriéroux, 2012[118]; Hafner et al , 2015[119]; Shimizu, 2014[120]).

Weather prediction based on machine learning technique called Support Vector Machines had been proposed (Radhika and M.Shashi, 2009)[121]. These algorithms have shown better results over the conventional algorithms and hence have a bright future for acceptance. For rainfall linear and nonlinear variability modeling, the Autoregressive Integrated Moving Average (ARIMA) models and ARCH family models have been used for predicting the monthly and annual rainfall series (Javari, 2016)[117]. Accurate estimation of rainfall has an important role in the optimal water resources management, as well as hydrological and climatological studies. Mehdizadeh et al. (2017)[122] investigated two novel types of hybrid models, namely gene expression programming-autoregressive conditional heteroscedasticity (GEP$\mathrm{ARCH}$ ) and artificial neural networks-autoregressive conditional heteroscedasticity (ANN-ARCH) to estimate monthly rainfall time series. They found that the proposed GEP-ARCH and ANN-ARCH models give a much better performance than the GEP and ANN in all of the investigated stations with various climates.

Moreover, the ANN-ARCH model mostly offers better performance in comparison with the GEP-ARCH model. As an innovation, the same authors introduced three new hybrid models by integrating soft computing methods including multivariate adaptive regression splines (MARS), Bayesian networks (BN) and GEP with a time series model, namely generalized autoregressive conditional heteroscedasticity $(\mathrm{GARCH})$ for modeling of the monthly precipitation (Mehdizadeh et al. 2017)[123]. Neural networks and statistical models are not opposing techniques for data analysis although there is an overlap between the two fields. Neural networks include several models, such as MLPs that are beneficial for statistical applications. Statistical methodology is directly applicable to neural networks in different ways such as optimization algorithms, estimation criteria, confidence intervals and graphical methods. The suggested successive steps in following weather, crop yield and cost forecasting are proposed by Mohan and Patil (2017)[124](Fig. 6). 
International Journal of Innovative Research in Electrical, Electronics, Instrumentation and Control Engineering

Vol. 6, Issue 8, August 2018

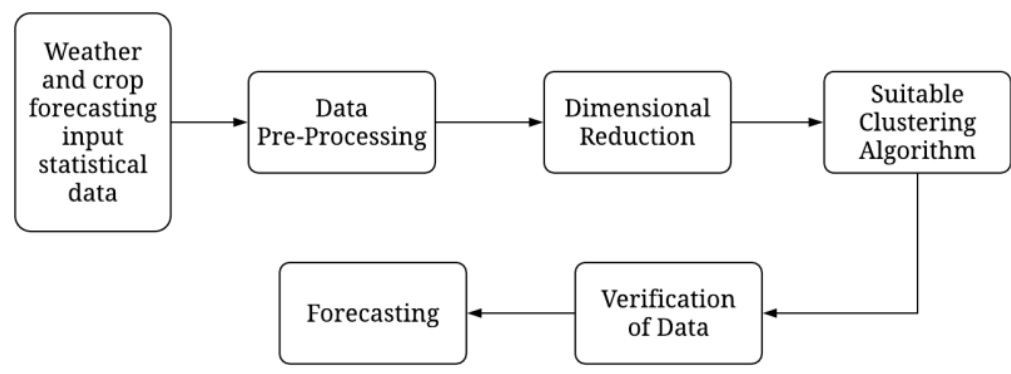

Fig. 6. General forecasting block diagram showing General steps followed in weather, crop yield and cost forecasting suggested by Mohan and Patil (2017)[124].

Laxmi et al. (2011)[125] worked on Neural Networks for crop yields forecasting using MLP with different learning algorithms at Utter Pradesh. They considered crop productivity, maximum and minimum temperature, relative humidity morning and rainfall as input variables. They used stepwise regression techniques significant variables for selecting significant variables. They concluded that ANN models produced better results than statistical model. MAPE was used for performance evaluation of models. Necessitate non-confirming.

\section{Smart Irrigation System}

In some of the old-fashioned irrigation system, irrigation is planned by monitoring the soil and water status by using tension meter. Farming sector consumes high labor cost in the fields for irrigation, which is a huge crisis being faced by farmers. In addition, a huge portion of water is consumed in developing countries due to absence of lacking automating controller system particularly in sandy soil. As well, the global warming results in climate changes and increasing droughts due to the daily dropping of the ground water level. In Egypt, The river water for irrigation is a big issue of dispute among many countries which share of the Nile waters. To overcome the shortage of water, some companies have come up with sensor based technology for smart agricultural irrigation. The Smart Irrigation System is used for the optimum amount of water in agricultural field without the involvement of farmer by using soil moisture Sensor that monitors the the level of water, soil temperature, nutrient content and weather forecasting (Gupta et al. 2016)[126]. The monitoring is performed by Microcontroller that automatically turn ON/OFF a pump according to the need of water for irrigation and hence is useful in saving water. Machine to machine (M2M) communication is developing technology which allows devices, objects to communicate among each other and send data to Server or Cloud through the Core Network (Shekhar et al. 2017)[127]. The current irrigation methodology adopted employ uniform water distribution (Edordu and Sacks, 2006 [128], Kim et al. 2008[129]) which is not optimal. So accordingly technologies being applied towards agricultural monitoring which is required by farmers So as such standalone monitoring station been developed employing "MSP 430" microcontroller along with set of meteorological sensors which includes temperature and humidity. In addition to the standalone monitoring station, Wireless Sensor based monitoring system (Deshpande and Prasad 2015)[130] been developed which is composed of number of wireless sensor nodes and a gateway. This system here provides a unique, wireless and easy solution with better spatial and temporal resolutions In addition to employing technologies in monitoring the agriculture for automating the irrigation system, there is need for some intelligence which allows machines to apply some intelligence in interpreting agricultural data captured and accordingly analyze data towards predicting the output rather than following traditional rule based algorithm.

Some investigator suggested M2M system which facilitate the connection of different devices without the need of interfering human. The system depends on the data recorded by temperature and moisture sensors to an IoT based automated irrigation system (Rumpf et al. 2010)[25] or sending the data through Bluetooth wireless transmitter (kim et al 2008)[129]. Wall and King (2004)[131] established an automated specific irrigation system with soil moisture sensor and sprinkler valve controller. These systems did not consider monitoring the water pollution and do not consider M2M communication model. Yang et al. (2007) [132] proposed monitoring system with a self-organizing intensive sensor based irrigation. The system construction consisted of bottom layer and upper layer as shown in Fig. 7 (left and right). Wall and King (2004)[131] developed a hierarchical wireless network architecture that was placed in the bottom and the nodes send the data that are receiving by the base station which is connected by wirelss LAN adjusted with software. To monitor and control the irrigation in the agricultural fields, Konstantinos et al. (2007)[133] developed an automated irrigation system (A2S) based on deploying sensor network with wireless sensors communicated among themselves to self-organize a wireless network. In this system, long distance communication between sensor network and server is brought by means of wireless LAN. The subsystem management includes database, application and web server. Data from sensors are received by the server which is stored in the database server. 


\section{International Journal of Innovative Research in Electrical, Electronics, Instrumentation and Control Engineering}

Vol. 6, Issue 8, August 2018
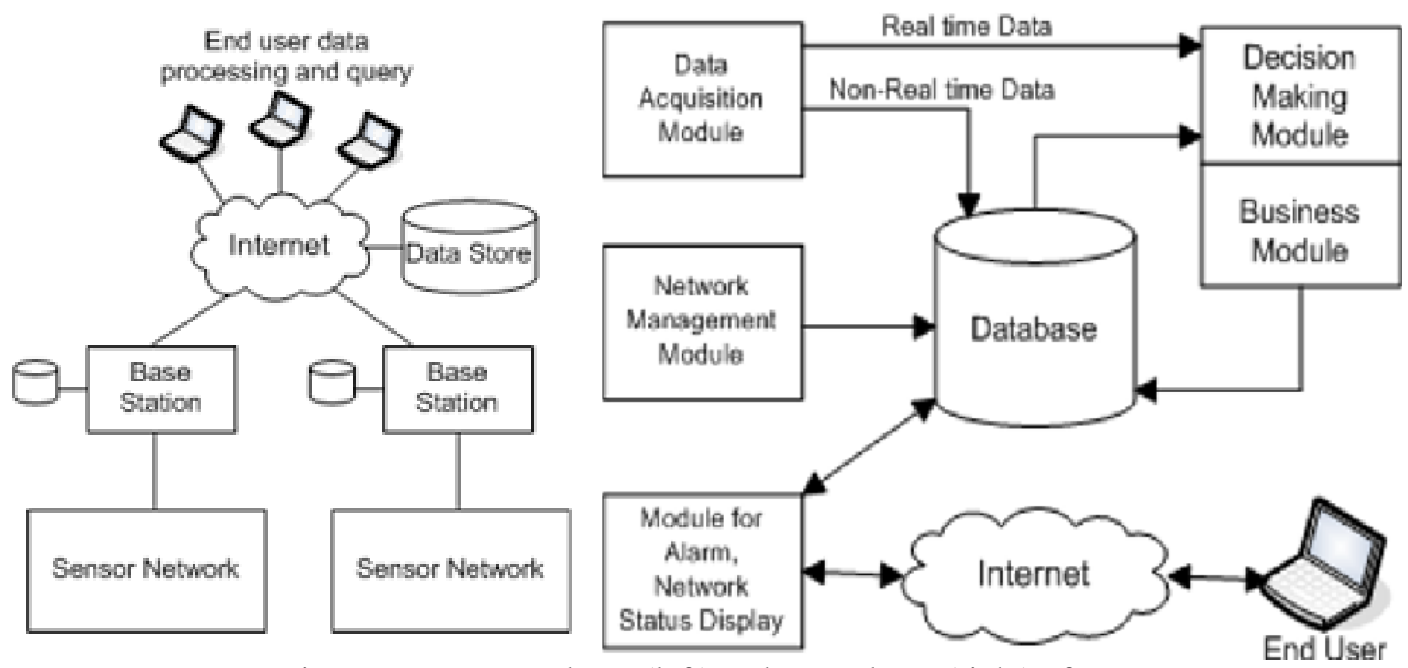

Figure. 7. F Bottom layer (left) and upper layer (right) of irrigation monitoring system designed by Shekhar et al. (2017)[127]

E. Species identification: The primary objective of plant systematics is the identification of plant species or group of species based on their characteristics and similarities. The identification of a species is followed by grouping or classification of similar species into a genus and grouping of similar genera to family and so on. The botanists use several criteria for classification including leaves, flowers, seeds, roots, stem, etc. Even with each previous item subclassification may be considered such as size, shape, color, texture, leaf veins, branching, seeds and seedlings of plants. Moreover, the taxonomy may be difficult due to the high number of species probably due to climatic and environmental conditions related to the variation in phytogeographical areas. Some expertized taxonomists develop technical keys which is classically limited to few number of species and usually with limited familiarity in plant recognition.

Due to the difficulties with the manual biological identification, and the difficulties of the taxonomic information language, vocabularies and formats of the manual classification key, several researchers suggested the automated identification. ANNs are a computing model imitative from the human brain and can basically simulate regular intelligence since they investigate skills and considered to be superior to other techniques. Moreover, they contain several numbers of interconnected operation elements known as neurons derived from the huge number of datasets (Mohamed, 2013[134], Pirouzmand and Dehdashti, 2015[135]). The system comprise 3 successive layers; an input layer, hidden layer, and output layer. They have the ability to learn, save and make relevance between inputs and outputs, which have the ability to be missed from experiential processes (Elsafi, 2014[136], Mattar, 2015[137]). This idea was trained by several workers including Leow et al. (2015)[138], Kalafi et al. (2016)[139], Morwenna et al. (2016)[140], Salimi et al. (2016)[141], Wong et al. (2016)[142], Kalafi et al. (2018)[143].

ANNs are powerful computational tools that have the ability for extrapolating their "knowledge" to new situations related to the classification. The recognition of a plant species involves several methods, the most important of which is the definition of the features followed by classification, segmentation, extraction and comparing the features to those from a labeled database. Feature variables (predictors), input variables whether individual or shared, are the input signals that offer the materials and data for pattern recognition. Each feature variable is weighted according to its importance (Haykin, 2008)[144]. The weight of each signal is summed and managed by activation function. Weight is actually the coefficient of each predictor. The signal processing technique can be mathematically denoted as:

$$
\mathrm{y}(\mathrm{x})=\Phi\left(\sum \mathrm{ni}=1 \mathrm{wi} \cdot \mathrm{xi}\right)
$$

where $\mathrm{y}$ is the output signal, $(\Phi)$ is the activation function, $\mathrm{x}$ is input variables and $\mathrm{w}$ is weight assigned to each input variables. Suppose there are $\mathrm{n}$ input variables. To better understand ANN, it can be compared to the regression model. Each input variable is in analogue to the predictors of a regression model.

Artificial neural networks (ANN) are one of early methodology utilized to identify organisms based on morphological characters due to its efficiency in management of large datasets and its generalizability. ANN technique was proposed for the identification and classification and has revealed adequate results in complex classifications of biological images and has proposed for the identification of wide variety of biological samples including insects e.g. mosquito (Banerjee et al., 2008[145]; Venkateswarlu et al., 2012[146], Lorenz et al. 2015[147]), honeybees (Roper et al. 2017[148]), tachinid flies (Diptera-Tachinidae), Onion thrips (Thysanoptera-Thripidae), Jumping plant-lice (Hemiptera-Psylloidea-Phacopteronidae) (VAŇHARA et al. 2006)[149], animal movement trajectories to link distance, 
International Journal of Innovative Research in Electrical, Electronics, Instrumentation and Control Engineering

Vol. 6, Issue 8, August 2018

resources, and memory (Dalziel et al. 2008)[150], animal behavior (Enquist and Ghirlanda, 2005[151], GutierrezGalan, 2018[152]), Recognition of frog, dogs and bird species from their sound (Pabico et al. 2015[153]), recognition of fish (Storbeck and Daan, 2001[154], White et al. 2006[155], Zion et al., 2007[156]; Hu et al., 2012[157]), butterfly species from Europe and South America using photographic images (Kang et al., 2012 [158], Hernández-Serna et al. 2014[159]), prediction for beef cattle thermal stress using weather and physiological variables (de Sousa et al., 2018)[160], identification of animals by bioacoustics (Chesmore, 2001 [161] and 2004[162]), identification of grasshoppers by their songs (Ohya and Chesmore, 2003)[163], Identification of bats by their echolocation calls (Parsons, 2001[164], Parsons and Jones, 2000[165]), Real-time bioacoustics monitoring and automated species identification including birds, frogs and insects from Puerto Rico and Costa Rica. (Aide et al. 2013)[166], algae (Coltelli et al. 2014)[167], etc.

Several workers utilized machine learning techniques for automated identification of plant species. Hearn (2009)[168] successfully developed a combination of Fourier analysis and Procrustes analysis to achieve species recognition with $72 \%$ accuracy using a large database consisting of 2420 leaves from 151 species variables. Clark et al. (2012)[169] trained ANN using leaf extracted features from herbarium specimens to recognize four species of the genus Tilia, and reached 44\% accuracy. Cope et al. (2012)[170] discussed a wide range of analytical methods employed in the identification of plant species using digital morphometric, computational, and image processing that have been proposed to analyze plant images. Aakif and FaisalKhan (2015)[171] extracted different morphological leaf features and used Fourier descriptors and a newly proposed shape-defining feature. Their trained algorithm using ANN gave more than 96\% accuracy. Akbar et al. (2018)[172] developed an ANN based prediction model by using the data of essential oil of 131 rhizome of turmeric (Curcuma longa L.) germplasms obtained from 8 agro-climatic regions. The researcher and his co-workers used 11 parameters for each sample for test and training the ANN model and the results revealed that multilayer-feed-forward neural networks with 12 nodes (MLFN-12) was the most favourable and model to employ with R2 value of 0.88. Sabzi and Abbaspour-Gilandeh (2018)[173] applied ANN- particle swarm optimization algorithm (PSO) method using Bayesian classifier for classification of the inputs as potato plants or weeds. The techniques achieved an accuracy of $99.0 \%$ and $71.7 \%$, respectively, for the test set. These results indicate that a accurate site-specific herbicide sprayer can be designed using the achieved approach, to get rid of the harmful weeds associated with potato plants and minimize the amount of the herbicide sprayed.

Many foliar features have been described using standard computer vision. The description include the whole leaf shape (Mokhtarian and Mackworth, 1992[174]. Wang et al., 2003[175], Wanga, 2008[176], Kadir et al. (2012)[177]), texture (Cope et al. 2010[178], Backes and Bruno, 2010[179], Kadir et al. 2012[177], Chaki et al., 2015[180], Naresh and Nagendraswamy, 2016)[181], veins pattern (Kadir et al. 2012[177], Chaki et al., 2015[180], Grinblat et al. 2016)[182], leaf shape (Zhao et al. 2015)[183] or color (Bama et al. 2011[184], Satti et al. 2013[185]). The classification systems proposed by most researchers include modified linear discriminant embedding algorithm (MLLDE) for leaf shape database with accuracy 93.5\% (Zhang and Lei, 2011)[186], probabilistic neural network (PNN) for leaf shape with accuracy 91.4\% (Hossain and Amin, 2010)[187], bisection of leaves with accuracy 92.5\% and leaf shape and veins with accuracy 95.8\% (Uluturk and Ugur, 2012)[188], and for texture with accuracy 95\% (Kadir et al. 2012)[177], Distributed Hierarchical Graph Neuron (DHGN) for pattern recognition and a k-Nearest Neighbor (k-NN) for classification of 2-D leaf shapes with accuracy 71.5\% (Amin and Khan, 2013)[189], Penalized discriminant Analysis (PDA) for legume leaf images with accuracy of $84.1 \%$ (Larese et al. 2014)[190], Local constrained Linear Coding (LLC) and Spatial Pyramid Matching (SPM) for medicinal plant with accuracy of 96.6\% (Wang et al. 2014) [191], Gray Tone Space-Dependent Matrices (GTSDM) and local binary pattern (LBP) operators for leaf texture of medicinal plants with accuracy of 94.7\% (Arun et al. 2012)[192], Artificial neural Network (ANN) for shape and color with accuracy of 93.3\% (Satti et al. 2013)[185] and for texture with accuracy of 87.1\% (Chaki et al. 2015)[180], Support Vector Machine (SVM) classifier for identification of herbal plants with accuracy 95\% (Fataniya et al. 2018)[191].

\section{CONCLUSION}

Agriculture is the back bone and important sector of several developing countries's economy. It contributes in the development and is considered as an important source of national income. The delay in manual discovery of the plant disease, crop yield prediction, inadequate timing irrigation, prediction of different various environmental factors or the recognition of plant species necessitate looking for advanced approach or specific modern innovation approach to replace the dependence on the manual application. The recent several computational techniques are steadily growing and help in facilitating and solving several agricultural difficulties. Several practices mainly using machine learning techniques can be used fundamentally to improve crop yield. Machine learning techniques depend on historic information, huge number of data and trained computer. The application of specific technique depend on the target upon which it will be employed. Mostly the techniques offer an accurate prediction of crop production. 


\section{International Journal of Innovative Research in Electrical, Electronics, Instrumentation and Control Engineering}

Vol. 6, Issue 8, August 2018

\section{REFERENCES}

[1] A.L. Samuel, "Some Studies in Machine Learning Using the Game of Checkers", IBM Journal of Research and Development, vol. 3, pp. 211229, 1959.

[2] B. Dickson, "Exploiting machine learning in cybersecurity", TechCrunch, -05-23, Retrieved 2017.

[3] M. N. Wernick, Y. Yang, J. G. Brankov, G. Yourganov and S. C. Strother, "Machine Learning in Medical Imaging," in IEEE Signal Processing Magazine, vol. 27, no. 4, pp. 25-38, July 2010.

[4] H. Mannila, "Data mining: machine learning, statistics, and databases," Proceedings of 8th International Conference on Scientific and Statistical Data Base Management, Stockholm, 1996, pp. 2-9.

[5] C.M. Bishop, "Pattern Recognition and Machine Learning", Springer, 2006. G. Kumar and P. K. Bhatia, "A Detailed Review of Feature Extraction in Image Processing Systems," 2014 Fourth International Conference on Advanced Computing \& Communication Technologies, 2014.

[6] G. Kumar and P. K. Bhatia, "A Detailed Review of Feature Extraction in Image Processing Systems," 2014 Fourth International Conference on Advanced Computing \& Communication Technologies, Rohtak, 2014, pp. 5-12. doi: 10.1109/ACCT.2014.74.

[7] H. A. Hiary, S. B. Ahmad, M. Reyalat, M. Braik, and Z. Alrahamneh, "Fast and Accurate Detection and Classification of Plant Diseases," International Journal of Computer Applications, vol. 17, no. 1, pp. 31-38, 2011

[8] H. Wang, G. Li, Z. Ma and X. Li, "Image recognition of plant diseases based on backpropagation networks," 2012 5th International Congress on Image and Signal Processing, Chongqing, 2012, pp. 894-900.

[9] J. G. A. Barbedo, "Digital image processing techniques for detecting, quantifying and classifying plant diseases," SpringerPlus, vol. 2, no. 1, 2013.

[10] S. D. Khirade and A. B. Patil, "Plant Disease Detection Using Image Processing," 2015 International Conference on Computing Communication Control and Automation, June, 2015, pp. 768-771.

[11] V. Singh and A. Misra, "Detection of plant leaf diseases using image segmentation and soft computing techniques," Information Processing in Agriculture, vol. 4, no. 1, pp. 41-49, 2017.

[12] S. Phadikar and J. Sil, "Rice disease identification using pattern recognition techniques," 2008 11th International Conference on Computer and Information Technology, Khulna, 2008, pp. 420-423.

[13] L. Liu and G. Zhou, "Extraction of the Rice Leaf Disease Image Based on BP Neural Network," 2009 International Conference on Computational Intelligence and Software Engineering, Wuhan, 2009, pp. 1-3.

[14] Q. Yao, Z. Guan, Y. Zhou, J. Tang, Y. Hu and B. Yang, "Application of Support Vector Machine for Detecting Rice Diseases Using Shape and Color Texture Features," 2009 International Conference on Engineering Computation, Hong Kong, 2009, pp. 79-83.

[15] N. N. Kurniawati, S. N. H. S. Abdullah, S. Abdullah and S. Abdullah, "Texture analysis for diagnosing paddy disease," 2009 International Conference on Electrical Engineering and Informatics, Selangor, 2009, pp. 23-27.

[16] G. Anthonys and N. Wickramarachchi, "An image recognition system for crop disease identification of paddy fields in Sri Lanka," 2009 International Conference on Industrial and Information Systems (ICIIS), Sri Lanka, 2009, pp. 403-407.

[17] K. Majid, Y. Herdiyeni and A. Rauf, "I-PEDIA: Mobile application for paddy disease identification using fuzzy entropy and probabilistic neural network," 2013 International Conference on Advanced Computer Science and Information Systems (ICACSIS), Bali, 2013, pp. 403-406.

[18] M. A. Kahar, S. Mutalib and A. Abdul-Rahman, "Early detection and classification of paddy diseases with neural networks and fuzzy logic," In Proceedings of the 17th International Conference on Mathematical and Computational Methods in Science and Engineering, MACMESE, pp. 248-257, 2015

[19] T. Suman and T. Dhruvakumar, "Classification of paddy leaf diseases using shape and color features," IJEEE vol. 7, no. 01, pp. 239-250, 2015.

[20] G. Tigistu and Y. Assabie, "Automatic identification of flower diseases using artificial neural networks," Africon $2015,2015$.

[21] S. I. S. S. B, "Disease Prediction of Paddy Crops Using Data Mining and Image Processing Techniques," International Journal of Advanced Research in Electrical, Electronics and Instrumentation Engineering, vol. 5, no. 5, pp. 3494-3502, 2016.

[22] M. Donatelli, R. Magarey, S. Bregaglio, L. Willocquet, J. Whish, and S. Savary, "Modelling the impacts of pests and diseases on agricultural systems," Agricultural Systems, vol. 155, pp. 213-224, 2017.

[23] F. K. V. Evert, S. Fountas, D. Jakovetic, V. Crnojevic, I. Travlos, and C. Kempenaar, "Big Data for weed control and crop protection," Weed Research, vol. 57, no. 4, pp. 218-233, 2017.

[24] G. Ruß, R. Kruse, M. Schneider and P. Wagner, "Data mining with neural networks for wheat yield prediction," In Industrial Conference on Data Mining, pp. 47-56. Springer, Berlin, Heidelberg, 2008.

[25] T. Rumpf, A.-K. Mahlein, U. Steiner, E.-C. Oerke, H.-W. Dehne, and L. Plümer, "Early detection and classification of plant diseases with Support Vector Machines based on hyperspectral reflectance," Computers and Electronics in Agriculture, vol. 74, no. 1, pp. 91-99, 2010.

[26] Z. H. Zhou, S.F. Chen, " Neural network ensemble. Chinese Journal of Computers. vol. 25(1), pp. 1-8, 2002.

[27] B. Chandrakarmokar, M. S. Ullah, M. K. Siddiquee, and K. M. R. Alam, "Tea Leaf Diseases Recognition using Neural Network Ensemble," International Journal of Computer Applications, vol. 114, no. 17, pp. 27-30, 2015.

[28] Lenz, H. Lee, and A. Saxena, "Deep learning for detecting robotic grasps," The International Journal of Robotics Research, vol. 34, no. 4-5, pp. 705-724, 2015.

[29] B. Alipanahi, A. Delong, M. T. Weirauch and B. J. Frey, "Predicting the sequence specificities of DNA-and RNA-binding proteins by deep learning," Nature biotechnology, vol. 33, no. 8, pp. 831-838, 2015.

[30] J. Arevalo, F. A. González, R. Ramos-Pollán, J. L. Oliveira and M. A. Guevara Lopez, "Convolutional neural networks for mammography mass lesion classification," 2015 37th Annual International Conference of the IEEE Engineering in Medicine and Biology Society (EMBC), Milan, 2015, pp. 797-800.

[31] Zhang, G.-S. Xia, T. Wu, L. Lin, and X. C. Tai, "Deep Learning for Remote Sensing Image Understanding," Journal of Sensors, vol. 2016, pp. $1-2,2016$.

[32] S. Wolfert, L. Ge, C. Verdouw, and M.-J. Bogaardt, "Big Data in Smart Farming - A review," Agricultural Systems, vol. 153 , pp. 69-80, 2017.

[33] S. B. Dhaygude and N. P. Kumbhar, "Agricultural plant leaf disease detection using image processing," International Journal of Advanced Research in Electrical, Electronics and Instrumentation Engineering, vol. 2, no. 1, pp. 599-602, 2013.

[34] H. Siddiqi, S. B. T. Sulaiman, I. Faye and I. Ahmad, "A real time specific weed discrimination system using multi-level wavelet decomposition," International Journal of Agriculture and Biology, vol. 11, no. 5, pp. 559-565, 2009

[35] S. Ananthi and S. V. Varthini, "Detection and classification of plant leaf diseases," International Journal of research in engineering \& applied Sciences, vol. 2, no. 2 , pp. 763-773, 2012

[36] R. C. Gonzalez, R. E. Woods, and B. R. Masters, "Digital Image Processing, Third Edition,” Journal of Biomedical Optics, vol. 14, no. 2, p. 029901, 2009. 


\title{
International Journal of Innovative Research in Electrical, Electronics, Instrumentation and Control Engineering
}

\author{
Vol. 6, Issue 8, August 2018
}

[37] V. Singh and A. Misra, "Detection of plant leaf diseases using image segmentation and soft computing techniques," Information Processing in Agriculture, vol. 4, no. 1, pp. 41-49, 2017

[38] F. Argenti, L. Alparone and G. Benelli, "Fast algorithms for texture analysis using co-occurrence matrices," in IEE Proceedings F - Radar and Signal Processing, vol. 137, no. 6, pp. 443-448, Dec. 1990

[39] M. K. Tripathi and D. D. Maktedar, "Recent machine learning based approaches for disease detection and classification of agricultural products," 2016 International Conference on Computing Communication Control and automation (ICCUBEA), 2016.

[40] K. P. Ferentinos, "Deep learning models for plant disease detection and diagnosis," Computers and Electronics in Agriculture, vol. 145, pp. 311-318, 2018

[41] Y. Shen, H. Zhou, J. Li, F. Jian, and D. S. Jayas, "Detection of stored-grain insects using deep learning," Computers and Electronics in Agriculture, vol. 145, pp. 319-325, 2018.

[42] P. Pukkela and S. Borra, "Machine Learning Based Plant Leaf Disease Detection and Severity Assessment Techniques: State-of-the-Art," Lecture Notes in Computational Vision and Biomechanics Classification in BioApps, pp. 199-226, 2017.

[43] A. Akhtar, A. Khanum, S. A. Khan, and A. Shaukat, "Automated Plant Disease Analysis (APDA): Performance Comparison of Machine Learning Techniques," 2013 11th International Conference on Frontiers of Information Technology, 2013.

[44] M. S. Sulaiman, H. Hashim, N. Abdullah, S. S. Rahmat, N. Wahid, A. F. M. Azmi, F. A. Ismail (2014). "Root Disease for Rubber Tree Based on Leaf Discoloration with Neural Network Technique" 2014 .Journal of Applied Science and Agriculture, vol, 9 no. 11, pp.: Special 341-351.

[45] P.T. Vanathi, , M. Preethi, G.S. Reddy "Identification of diseases in leaves using machine vision" International Journal of Electrical, Electronicsa Data Communication vol. 5 no. 4 pp. 41045.

[46] S. Bashir and N. Sharma, "Remote Area Plant Disease Detection Using Image Processing," IOSR Journal of Electronics and Communication Engineering, vol. 2, no. 6, pp. 31-34, 2012.

[47] J. Frausto-Solis, A. Gonzalez-Sanchez, and M. Larre, "A New Method for Optimal Cropping Pattern,” MICAI 2009: Advances in Artificial Intelligence Lecture Notes in Computer Science, pp. 566-577, 2009.

[48] J. Liu, C. E. Goering, and L. Tian, “A Neural Network For Setting Target Corn Yields,” Transactions of the ASAE, vol. 44, no. 3, pp. 705-713, 2001.

[49] G. Ruß, "Data Mining of Agricultural Yield Data: A Comparison of Regression Models," Advances in Data Mining. Applications and Theoretical Aspects Lecture Notes in Computer Science, pp. 24-37, 2009

[50] S. Ghosh and S. Koley, "Machine learning for soil fertility and plant nutrient management using back propagation neural networks," International Journal on Recent and Innovation Trends in Computing and Communication ISSN: 2321-8169, Vol. 2, no. 2, pp. 292 - $297,2010$.

[51] S. Mishra, D. Mishra, and G. H. Santra, "Applications of Machine Learning Techniques in Agricultural Crop Production: A Review Paper," Indian Journal of Science and Technology, vol. 9, no. 38, 2016

[52] W. Okori and J. Obua, "Machine learning classification technique for famine prediction," In Proceedings of the world congress on engineering, vol. 2, pp. 991-996, 2011

[53] D. Snehal, and Sandeep, V. “Agricultural crop yield prediction using artificial neural network approach" 2014, Int. J. Innov. Res. Elect. Electr. Instrum. Cont. Eng.vol.. 2., pp. 683-686.

[54] R. Kumar, M. P. Singh, P. Kumar and J. P. Singh, "Crop Selection Method to maximize crop yield rate using machine learning technique," 2015 International Conference on Smart Technologies and Management for Computing, Communication, Controls, Energy and Materials (ICSTM), Chennai, 2015, pp. 138-145.

[55] K. A. Shastry, H. Sanjay, and A. Deshmukh, "A Parameter Based Customized Artificial Neural Network Model for Crop Yield Prediction," Journal of Artificial Intelligence, vol. 9, no. 1, pp. 23-32, Jan. 2016.

[56] S. P. Serbin, D. N. Dillaway, E. L. Kruger, and P. A. Townsend, "Leaf optical properties reflect variation in photosynthetic metabolism and its sensitivity to temperature," Journal of Experimental Botany, vol. 63, no. 1, pp. 489-502, Jun. 2011.

[57] E. A. Ainsworth, S. P. Serbin, J. A. Skoneczka, and P. A. Townsend, "Using leaf optical properties to detect ozone effects on foliar biochemistry," Photosynthesis Research, vol. 119, no. 1-2, pp. 65-76, Sep. 2013.

[58] C. R. Yendrek, T. Tomaz, C. M. Montes, Y. Cao, A. M. Morse, P. J. Brown, L. M. Mcintyre, A. D. Leakey, and E. A. Ainsworth, "HighThroughput Phenotyping of Maize Leaf Physiological and Biochemical Traits Using Hyperspectral Reflectance," Plant Physiology, vol. 173, no. 1 , pp. 614-626, 2016.

[59] D. Gillon, C. Houssard, and R. Joffre, "Using near-infrared reflectance spectroscopy to predict carbon, nitrogen and phosphorus content in heterogeneous plant material," Oecologia, vol. 118, no. 2, pp. 173-182, 1999.

[60] Y. Zhai, L. Cui, X. Zhou, Y. Gao, T. Fei, and W. Gao, "Estimation of nitrogen, phosphorus, and potassium contents in the leaves of different plants using laboratory-based visible and near-infrared reflectance spectroscopy: comparison of partial least-square regression and support vector machine regression methods," International Journal of Remote Sensing, vol. 34, no. 7, pp. 2502-2518, Oct. 2013.

[61] S. Wang, X. Chen, Q. Wang, P. Li, and X. Cao, "Identification of the best spectral indices to remotely trace the diurnal course of water use efficiency of Tamarix ramosissima in the Gurbantunggut Desert, China," Environmental Earth Sciences, vol. 65, no. 1, pp. 11-20, 2011.

[62] W. Wang, X. Yao, X. Yao, Y. Tian, X. Liu, J. Ni, W. Cao, and Y. Zhu, "Estimating leaf nitrogen concentration with three-band vegetation indices in rice and wheat," Field Crops Research, vol. 129, pp. 90-98, 2012.

[63] C. Atzberger, M. Guérif, F. Baret, and W. Werner, "Comparative analysis of three chemometric techniques for the spectroradiometric assessment of canopy chlorophyll content in winter wheat," Computers and Electronics in Agriculture, vol. 73, no. 2, pp. 165-173, 2010

[64] B.W.Penning, , C.T. Hunter, R. Tayengwa, A.L. Eveland, C.K. Dugard, A.T. Olek, W. Vermerris, K.E. Koch, D.R. McCarty, M. F. Davis, et al. "Genetic Resources for Maize Cell Wall Biology" Plant Physiology, vol. 151, pp.1703-1728, 2009.

[65] J. J. Couture, S. P. Serbin, and P. A. Townsend, "Spectroscopic sensitivity of real-time, rapidly induced phytochemical change in response to damage," New Phytologist, vol. 198, no. 1, pp. 311-319, May 2013.

[66] F. Jia, G. Liu, S. Ding, Y. Yang, Y. Fu, and Z. Wang, "Using leaf spectral reflectance to monitor the effects of shading on nicotine content in tobacco leaves," Industrial Crops and Products, vol. 51, pp. 444-452, 2013.

[67] Y. Liu, H. Chen, G. Wu, and X. Wu, "Feasibility of estimating heavy metal concentrations in Phragmites australis using laboratory-based hyperspectral data-A case study along Le'an River, China," International Journal of Applied Earth Observation and Geoinformation, vol. 12, 2010

[68] H. Xu, S. Zhu, Y. Ying, and H. Jiang, “Application of multispectral reflectance for early detection of tomato disease," Optics for Natural Resources, Agriculture, and Foods, 2006.

[69] A.-K. Mahlein, E.-C. Oerke, U. Steiner, and H.-W. Dehne, "Recent advances in sensing plant diseases for precision crop protection," European Journal of Plant Pathology, vol. 133, no. 1, pp. 197-209, 2012.

[70] T. Borregaard, H. Nielsen, L. Norgaard, , and H. Have, "Crop Weed Discrimination by Line Imaging Spectroscopy, Journal of Agricultural Engineering Research, vol. 75, pp.389-400, 2000

[71] K. Manevski, I. Manakos, G. P. Petropoulos, and C. Kalaitzidis, "Discrimination of common Mediterranean plant species using field spectroradiometry," International Journal of Applied Earth Observation and Geoinformation, vol. 13, no. 6, pp. 922-933, 2011. 


\section{International Journal of Innovative Research in Electrical, Electronics, Instrumentation and Control Engineering}

Vol. 6, Issue 8, August 2018

[72] D. Heckmann, U. Schlüter, and A. P. Weber, "Machine Learning Techniques for Predicting Crop Photosynthetic Capacity from Leaf Reflectance Spectra," Molecular Plant, vol. 10, no. 6, pp. 878-890, 2017.

[73] C.C. House, "Forecasting Corn Yields: A Comparison Study Using Missouri Data, Statistical Research Division, United States Department of Agriculture, vol.17(16), pp.3189-3200, 1979.

[74] J. Matis, T. Birkett, and D. Boudreaux, "An application of the Markov chain approach to forecasting cotton yields from surveys," Agricultural Systems, vol. 29, no. 4, pp. 357-370, 1989.

[75] M. Shibayama and T. Akiyama, "Estimating grain yield of maturing rice canopies using high spectral resolution reflectance measurements," Remote Sensing of Environment, vol. 36, no. 1, pp. 45-53, 1991.

[76] Yiqun Gu-D.r. Peiris-J.w. Crawford-J.w. Ncnicol-B. Marshall-R.a. Jefferies - Proceedings of the Tenth Conference on Artificial Intelligence for Applications

[77] D. Stathakis, I. Savin and T. Nègre, "Neuro-fuzzy modeling for crop yield prediction," The International Archives of the Photogrammetry, Remote Sensing and Spatial Information Sciences, vol. 34, no. Part XXX, pp. 1-4, 2006.

[78] R. C. Jain and V. Ramasubramanian, "Forecasting of crop yields using second order Markov Chains," Journal of the Ind. Soc. of Agril. Stats, vol. 51, no. 1, pp. 61-72, 1998.

[79] A. Wilcox, N. H. Perry, N. D. Boatman, and K. Chaney, "Factors affecting the yield of winter cereals in crop margins," The Journal of Agricultural Science, vol. 135 , no. 4, pp. 335-346, 2000.

[80] A. Oludhe, "Deterministic and Probabilistic prediction approaches in Seasonal to Inter-annual climate forecasting," Applications of Climate Forecasts for Agriculture, pp. 39-48, 2002.

[81] V. Petridis and V. G. Kaburlasos, "FINkNN: A fuzzy interval number k-nearest neighbor classifier for prediction of sugar production from populations of samples," Journal of Machine Learning Research, vol. 4, pp. 17-37, 2003.

[82] P. A. Paul and G. P. Munkvold, "Regression and Artificial Neural Network Modeling for the Prediction of Gray Leaf Spot of Maize," Phytopathology, vol. 95, no. 4, pp. 388-396, 2005.

[83] D. Jiang, X. Yang, N. Clinton, and N. Wang, "An artificial neural network model for estimating crop yields using remotely sensed information," International Journal of Remote Sensing, vol. 25, no. 9, pp. 1723-1732, 2004.

[84] M. Kaul, R. L. Hill, and C. Walthall, “Artificial neural networks for corn and soybean yield prediction,” Agricultural Systems, vol. 85, no. 1, pp. $1-18,2005$.

[85] K.M. Monisha, L. Robert, H. Hill, C. Walthall, "Artificial neural networks for corn and Soybean yield prediction", Elsevier. Agricultural System. Vol. 85(1), pp. 1-18, 2005.

[86] C. Chen and H. Mcnairn, "A neural network integrated approach for rice crop monitoring," International Journal of Remote Sensing, vol. 27, no. 7, pp. 1367-1393, 2006

[87] A. Shabri, R. Samsudin, and Z. Ismail, "Forecasting of the Rice Yields Time Series Forecasting using Artificial Neural Network and Statistical Model," Journal of Applied Sciences, vol. 9, no. 23, pp. 4168-4173, Jan. 2009.

[88] G. Gorni and A. Augusto, "The Application of Neural Networks in the Modeling of Plate Rolling Processes," JOM. The Minerals, Metals and Material Society, vol. 49, no. 4, pp. 1-4, 2008

[89] S.R.K. Priya, K.K. Suresh, "A study on pre-harvest forecast of sugarcane yield using climatic variables”, Statistics and Applications, Vol. 8(2), pp. 1-8, 2009.

[90] S. Veenadhari, D. B. Mishra, and D. Singh, "Soybean Productivity Modelling using Decision Tree Algorithms," International Journal of Computer Applications, vol. 27, no. 7, pp. 11-15, 2011.

[91] M. N. M. Salleh, "A fuzzy modelling of decision support system for crop selection," 2012 IEEE Symposium on Industrial Electronics and Applications, 2012.

[92] L. Hong-Ying, H. Yan-Lin, Z. Yong-Juan, and Z. Hui-Ming, "Crop Yield Forecasted Model Based on Time Series Techniques," Journal of Northeast Agricultural University (English edition), vol. 19, no. 1, pp. 73-77, 2012.

[93] A. V. T. V. Kumar and R. R. Kanth, "A data mining approach for the estimation of climate change on the jowar crop yield in India," International Journal of Emerging Science and Engineering (IJESE), vol. 2, no. 2, pp. 16-20, 2013.

[94] E. Papageorgiou, K. Aggelopoulou, T. Gemtos, and G. Nanos, "Yield prediction in apples using Fuzzy Cognitive Map learning approach," Computers and Electronics in Agriculture, vol. 91, pp. 19-29, 2013.

[95] P.P. Prasad, S.A. Begum, “Regression and NeuraNnetworks Models for Prediction of Crop Production”, International Journal of Scientific and Engineering Research, vol. 4(9), pp.98-108, 2013.

[96] G. N. Fathima and R. Geetha, "Agriculture crop pattern using data mining techniques," International Journal of Advanced Research in Computer Science and Software Engineering, vol. 4, no. 5, pp. 781-786, 2014

[97] P. Utkarsha, N. Narkhede, K.P. Adhiya, "Evaluation of Modified K-Means Clustering Algorithm in Crop Prediction. International Journal of Advanced Computer Research, vol. 4(3), pp. 799-807, 2014.

[98] S. S. Dahikar and S. V. Rode, "Agricultural crop yield prediction using artificial neural network approach," International Journal of Innovative Research in Electrical, Electronics, Instrumentation and Control Engineering, vol. 2, no. 1, pp. 683-686, 2014.

[99] J. Osman, J. Inglada, and J.-F. Dejoux, "Assessment of a Markov logic model of crop rotations for early crop mapping," Computers and Electronics in Agriculture, vol. 113, pp. 234-243, 2015.

[100]R. Sujatha and P. Isakki, "A study on crop yield forecasting using classification techniques," 2016 International Conference on Computing Technologies and Intelligent Data Engineering (ICCTIDE16), 2016.

[101]N. Hemageetha, "A survey on application of data mining techniques to analyze the soil for agricultural purpose," In Computing for Sustainable Global Development (INDIACom), 2016 3rd International Conference on, pp. 3112-3117, 2016.

[102]V. Sellam and E. Poovammal, "Prediction of Crop Yield using Regression Analysis," Indian Journal of Science and Technology, vol. 9, no. 38, 2016.

[103]T. M. Giannaros, D. Melas, and I. Ziomas, "Performance evaluation of the Weather Research and Forecasting (WRF) model for assessing wind resource in Greece," Renewable Energy, vol. 102, pp. 190-198, 2017.

[104]S. T. Drummond, K. A. Sudduth, A. Joshi, S. J. Birrell, and N. R. Kitchen, "Statistical And Neural Methods For Site-Specific Yield Prediction," Transactions of the ASAE, vol. 46, no. 1, 2003.

[105]W. Schlenker and M. Roberts, "Estimating the Impact of Climate Change on Crop Yields: The Importance of Nonlinear Temperature Effects," 2008

[106]B. Safa, A. Khalili, M. Teshnehlab and A. Liaghat, "Artificial neural networks application to predict wheat yield using climatic data," In Proceedings of 20th International Conference on IIPS, pp. 1-39. Iranian Meteorological Organization, 2004.

[107]G. G. Wilkerson, J. W. Jones, K. J. Boote, K. T. Ingram, and J. W. Mishoe, "Modeling Soybean Growth for Crop Management," Transactions of the ASAE, vol. 26, no. 1, pp. 0063-0073, 1983.

[108]J. R. Porter, "AFRCWHEAT2: A model of the growth and development of wheat incorporating responses to water and nitrogen," European Journal of Agronomy, vol. 2, no. 2, pp. 69-82, 1993 


\title{
International Journal of Innovative Research in Electrical, Electronics, Instrumentation and Control Engineering
}

\author{
Vol. 6, Issue 8, August 2018
}

[109]Jamieson, M. Semenov, I. Brooking, and G. Francis, "Sirius: a mechanistic model of wheat response to environmental variation," European Journal of Agronomy, vol. 8, no. 3-4, pp. 161-179, 1998.

[110]C. A. Jones, J. R. Kiniry, P. T. Dyke,"CERES-Maize: A Simulation Model of Maize Growth and Development”, Texas A\& M University Press, 1986.

[111]C. J. T. Spitters, H. Van Keulen, D. W. G. Van Kraailingen, "A simple but Universal Crop Growth Simulation Model, SUCRO87," Simulation and Systems Management in Crop Protection. Simulation Monographs, PUDOC, Wageningen, The Netherlands, 1988.

[112]J. Goudriaan and H. H. V. Laar, "Development and growth," Modelling Potential Crop Growth Processes Current Issues in Production Ecology, pp. 69-94, 1994.

[113]N. Brisson, B. Mary, D. Ripoche, M. H. Jeuffroy, F. Ruget, B. Nicoullaud, P. Gate, F. Devienne-Barret, R. Antonioletti, C. Durr, G. Richard, N. Beaudoin, S. Recous, X. Tayot, D. Plenet, P. Cellier, J.-M. Machet, J. M. Meynard, and R. Delécolle, "STICS: a generic model for the simulation of crops and their water and nitrogen balances. I. Theory and parameterization applied to wheat and corn," Agronomie, vol. 18, no. 5-6, pp. 311-346, 1998.

[114]V. Varcoe, "A note on the computer simulation of crop growth in agricultural land evaluation," Soil Use and Management, vol. 6, no. 3, pp. $157-160,1990$.

[115]F. Engle, "Autoregressive Conditional Heteroscedasticity with Estimates of the Variance of United Kingdom Inflation," Econometrica, vol. 50, no. 4 , p. 987,1982 .

[116]A. A. Weiss, "ARMA models with ARCH errors," Journal of time series analysis, vol. 5, no. 2, pp. 129-143, 1984.

[117]M. Javari, "Spatial-temporal Variability of Seasonal Precipitation in Iran,” The Open Atmospheric Science Journal, vol. 10, no. 1, pp. 84-102, 2016.

[118]C. Gouriéroux, "Some Applications of Univariate ARCH Models," ARCH Models and Financial Applications Springer Series in Statistics, pp. 67-103, 1997.

[119]C. M. Hafner and A. Preminger, “An ARCH model without intercept,” Economics Letters, vol. 129, pp. 13-17, 2015.

[120]K. Shimizu, "Bootstrapping the nonparametric ARCH regression model," Statistics \& Probability Letters, vol. 87, pp. 61-69, 2014.

[121]Y. Radhika and M. Shashi, "Atmospheric Temperature Prediction using Support Vector Machines," International Journal of Computer Theory and Engineering, pp. 55-58, 2009.

[122]Mehdizadeh, J. Behmanesh, and K. Khalili, "New Approaches for Estimation of Monthly Rainfall Based on GEP-ARCH and ANN-ARCH Hybrid Models," Water Resources Management, vol. 32, no. 2, pp. 527-545, May 2017.

[123] Mehdizadeh, J. Behmanesh, and K. Khalili, "A comparison of monthly precipitation point estimates at 6 locations in Iran using integration of soft computing methods and GARCH time series model," Journal of Hydrology, vol. 554, pp. 721-742, 2017.

[124] P. Mohan, K.K. Patil, " Survey on Crop and Weather Forecasting based on Agriculture Related Statistical Data. International Journal of Innovative Research in Computer and Communication Engineering vol. 5 (2), pp. 2244-2248, 2017.

[125]R. R. Laxmi and A. Kumar, "Weather based forecasting model for crops yield using neural network approach," Statistics and Applications, vol. 9, no. 1, pp. 59-69, 2011.

[126] A. Gupta, S. Mishra, N. D. Bokde, K.D. Kulat, K.D. "Need of Smart Water Systems in India. Vol. 11, pp. 2216-2223, 2016.

[127]Shekhar, Y., Dagur, E., Mishra, S. (2017). Intelligent IoT Based Automated Irrigation System. International Journal of Applied Engineering Research, 12(18): 7306-7320.

[128]C. Edordu, L. Sacks, "Self Organizing Wireless Sensor Networks as a Land Management Tool in Developing Countries: A Preliminary Survey," In Proceedings of the 2006 London Communications Symposium, Communications Engineering Doctorate Centre, London, UK, 2006.

[129]Y. Kim, R. Evans, and W. Iversen, "Remote Sensing and Control of an Irrigation System Using a Distributed Wireless Sensor Network," IEEE Transactions on Instrumentation and Measurement, vol. 57, no. 7, pp. 1379-1387, 2008

[130]V. A. Deshpande and J. P. Prasad, "Automated Irrigation System Using a Wireless Sensor Network and GPRS Module," Proceedings of Second International Conference on Signal Processing, Image Processing and VLSI, 2015.

[131]R. W. Wall and B. A. King, "Incorporating Plug and Play Technology into Measurement and Control Systems for Irrigation Management," 2004, Ottawa, Canada August 1 - 4, 2004, 2004.

[132]W. Yang, H. Liusheng, W. Junmin, X. Hongli, "Wireless Sensor Networks for Intensive Irrigated Agriculture," Consumer Communications and Networking Conference, 2007. CCNC 2007. 4th IEEE, pp.197-201, Las Vegas, Nevada, Jan. 2007

[133]K. Konstantinos, X. Apostolos, K. Panagiotis, and S. George, "Topology Optimization in Wireless Sensor Networks for Precision Agriculture Applications," 2007 International Conference on Sensor Technologies and Applications (SENSORCOMM 2007), 2007.

[134]H. I. Mohamed, "Design of alluvial Egyptian irrigation canals using artificial neural networks method," Ain Shams Engineering Journal, vol. 4, no. 2, pp. 163-171, 2013.

[135]A. Pirouzmand and M. K. Dehdashti, "Estimation of relative power distribution and power peaking factor in a VVER-1000 reactor core using artificial neural networks," Progress in Nuclear Energy, vol. 85, pp. 17-27, 2015.

[136]S. H. Elsafi, "Artificial Neural Networks (ANNs) for flood forecasting at Dongola Station in the River Nile, Sudan," Alexandria Engineering Journal, vol. 53, no. 3, pp. 655-662, 2014

[137]M. Mattar, A. Alazba, and T. Z. El-Abedin, "Forecasting furrow irrigation infiltration using artificial neural networks," Agricultural Water Management, vol. 148, pp. 63-71, 2015.

[138]L. K. Leow, L.-L. Chew, V. C. Chong, and S. K. Dhillon, "Automated identification of copepods using digital image processing and artificial neural network," BMC Bioinformatics, vol. 16, no. Suppl 18, 2015.

[139] Kalafi EY, Tan WB, Town C, Dhillon SK.2016. Automated identification of monogeneans using digital image processing and K-nearest neighbour approaches. BMC Bioinf. 17:511. doi: 10.1186/s12859-016-1376-

[140]S. Morwenna, S. Marsham, C.W. Chang, V.C. Chong, A. Sasekumar, K.D. Sarinder KD, K.H. Loh, "The Use of Otolith Morphometrics in Determining the Size and Species Identification of Eight Mullets (Mugiliformes: Mugilidae) from Malaysia. Sains Malays, vol. 45 (5), pp.735743, 2016.

[141]N. Salimi, K. H. Loh, S. K. Dhillon, and V. C. Chong, "Fully-automated identification of fish species based on otolith contour: using short-time Fourier transform and discriminant analysis (STFT-DA)," PeerJ, vol. 4, 2016.

[142]J. Y. Wong, C. Chu, V. C. Chong, S. K. Dhillon, and K. H. Loh, "Automated otolith image classification with multiple views: an evaluation on Sciaenidae," Journal of Fish Biology, vol. 89, no. 2, pp. 1324-1344, 2016

[143]E. Y. Kalafi, C. Town, and S. K. Dhillon, "How automated image analysis techniques help scientists in species identification and classification?," Folia Morphologica, vol. 77, no. 2, pp. 179-193, Jun. 2018.

[144] S.O. Haykin, editor. "Neural networks and learning machines". 3rd ed. New Jersey: Prentice Hall, 2008.

[145]A. K. Banerjee, K. Kiran, U. Murty, and C. Venkateswarlu, "Classification and identification of mosquito species using artificial neural networks," Computational Biology and Chemistry, vol. 32, no. 6, pp. 442-447, 2008. 


\title{
International Journal of Innovative Research in Electrical, Electronics, Instrumentation and Control Engineering
}

\author{
Vol. 6, Issue 8, August 2018
}

[146]C. Venkateswarlu, K. Kiran, and J. S. Eswari, “A Hierarchical Artificial Neural System For Genera Classification And Species Identification In Mosquitoes,” Applied Artificial Intelligence, vol. 26, no. 10, pp. 903-920, 2012.

[147]C. Lorenz, A. S. Ferraudo, and L. Suesdek, "Artificial Neural Network applied as a methodology of mosquito species identification," Acta Tropica, vol. 152, pp. 165-169, 2015.

[148]M. Roper, C. Fernando, and L. Chittka, "Insect Bio-inspired Neural Network Provides New Evidence on How Simple Feature Detectors Can Enable Complex Visual Generalization and Stimulus Location Invariance in the Miniature Brain of Honeybees," PLOS Computational Biology, vol. 13, no. 2, Mar. 2017.

[149]J. VAŇHARA, N. MURÁRIKOVÁ, P. FEDOR, I. MALENOVSKÝ, J. HAVEL. Artificial Neural Nnetworks for Insect Identification. In Proceedings of the 6th International Congress of Dipterology. Fukuoka, Japan: Comittee of the 6th International Congress of Dipterology, pp. 289-290, 2 s, 2006.

[150]B.D. Dalziel, J.M. Morales, J.M. Fryxell, "Fitting probability distributions to animal movement trajectories: using artificial neural networks to link distance, resources, and memory". The American Naturalist, vol 172, pp. 248-258, 2008.

[151]M. Enquist, S. Ghirlanda, “ Neural Networks and Animal Behavior". Princeton Univesity Press, Princeton, 2005.

[152]D. Gutierrez-Galan, J. P. Dominguez-Morales, E. Cerezuela-Escudero, A. Rios-Navarro, R. Tapiador-Morales, M. Rivas-Perez, M. DominguezMorales, A. Jimenez-Fernandez, and A. Linares-Barranco, "Embedded neural network for real-time animal behavior classification," Neurocomputing, vol. 272, pp. 17-26, 2018.

[153]J. P. Pabico, A. M. V. Gonzales, M.J.S. Villanueva, A. a. Mendoza, A. A. "Automatic Identification of Animal Breeds and Species Using Bioacoustics and Artificial Neural Networks" arXiv:1507.05546v1 [cs.SD] 20 Jul 2015.

[154]F. Storbeck and B. Daan, "Fish species recognition using computer vision and a neural network," Fisheries Research, vol. 51, no. 1, pp. 11-15, 2001.

[155]D. White, C. Svellingen, and N. Strachan, “Automated measurement of species and length of fish by computer vision," Fisheries Research, vol. 80, no. 2-3, pp. 203-210, 2006.

[156]B. Zion, V. Alchanatis, V. Ostrovsky, A. Barki, and I. Karplus, "Real-time underwater sorting of edible fish species," Computers and Electronics in Agriculture, vol. 56, no. 1, pp. 34-45, 2007.

[157]J. Hu, D. Li, Q. Duan, Y. Han, G. Chen, and X. Si, "Fish species classification by color, texture and multi-class support vector machine using computer vision," Computers and Electronics in Agriculture, vol. 88, pp. 133-140, 2012.

[158]S.-H. Kang, S.-H. Song, and S.-H. Lee, "Identification of butterfly species with a single neural network system," Journal of Asia-Pacific Entomology, vol. 15, no. 3, pp. 431-435, 2012.

[159] A. Hernández-Serna, L.F. Jiménez-Segura, "Peer Review \#2 of “Automatic identification of species with neural networks (v0.1)",” Apr. 2014. https://doi.org/10.7717/peerj.563.

[160]R. V. D. Sousa, A. V. D. S. Rodrigues, M. G. D. Abreu, R. A. Tabile, and L. S. Martello, "Predictive model based on artificial neural network for assessing beef cattle thermal stress using weather and physiological variables," Computers and Electronics in Agriculture, vol. 144, pp. 3743, 2018.

[161]E. Chesmore, "Application of time domain signal coding and artificial neural networks to passive acoustical identification of animals," Applied Acoustics, vol. 62, no. 12, pp. 1359-1374, 2001

[162]D. Chesmore, "Automated bioacoustic identification of species," Anais da Academia Brasileira de Ciências, vol. 76, no. 2, pp. 436-440, 2004.

[163]E. Ohya E. D. Chesmore, "Automated Identification of Grasshoppers by their Songs. Iwate University, Morioka, Japan: Annual Meeting of the Japanese Society of Applied Entomology and Zoology, 2003.

[164] S. Parsons, "Identification of New Zealand bats (Chalinolobus tuberculatus and Mystacina tuberculata) in flight from analysis of echolocation calls by artificial neural networks," Journal of Zoology, vol. 253, no. 4, pp. 447-456, 2001.

[165]S. Parsons, G. Jones, “ Acoustic Identification of Twelve Species of Echolocating Bat by Discriminant Function Analysis and Artificial Neural Networks. The Journal of Experimental Biology, vol. 203, pp. 2641-2656, 2000.

[166]T.M. Aide, C. Corrada-Bravo, C., M. Campos-Cerqueira, C. Milan, G. Vega, R. Alvarez, "Real-time bioacoustics monitoring and automated species identification. Peer Journal, 1, e103, 2013. http://doi.org/10.7717/peerj.103

[167]P. Coltelli, L. Barsanti, V. Evangelista, A. M. Frassanito, and P. Gualtieri, "Water monitoring: automated and real time identification and classification of algae using digital microscopy,” Environ. Sci.: Processes Impacts, vol. 16, no. 11, pp. 2656-2665, 2014

[168]D. Hearn, "Shape analysis for the automated identification of plants from images of leaves", Taxon 58(3):934-954.2009.

[169]J. Y. Clark, D. P. Corney, H.L.Tang, "Automated plant identification using artificial neural networks", Proceedings of the IEEE Symposium on Computational Intelligence in Bioinformatics and Computational Biology CIBCB 2012, May 9-12; San Diego, CA: IEEE. doi: 10.1109/CIBCB.2012.6217215.

[170]J. S. Cope, P. Remagnino, S. Barman, and P. Wilkin, "Plant Texture Classification Using Gabor Co-occurrences," Advances in Visual Computing Lecture Notes in Computer Science, pp. 669-677, 2010.

[171]A. Aakif and M. F. Khan, "Automatic classification of plants based on their leaves," Biosystems Engineering, vol. 139, pp. 66-75, 2015.

[172] A. Akbar, A. Kuanar, J. Patnaik, A. Mishra, and S. Nayak, "Application of Artificial Neural Network modeling for optimization and prediction of essential oil yield in turmeric (Curcuma longa L.)," Computers and Electronics in Agriculture, vol. 148, pp. 160-178, 2018.

[173]S. Sabzi and Y. Abbaspour-Gilandeh, "Using video processing to classify potato plant and three types of weed using hybrid of artificial neural network and partincle swarm algorithm," Measurement, vol. 126, pp. 22-36, 2018.

[174]F. Mokhtarian and A. K. Mackworth, "A theory of multiscale,curvature-based shape representation for planar curves,"IEEE Transactions on Pattern Analysis and Machine Intelligence, vol. 14, pp. $789-805,1992$

[175]Z. Wang, Z. Chi, and D. Feng, "Shape based leaf image re-trieval,"VISP, pp. 34 - 43, 2003.

[176]X. F. Wanga, D. S Huanga, J. X Dua, H. Xua, and L. Heutted, "Classification of plant leaf images with complicated back-ground," AMC, pp. 916-926, 2008

[177]A. Kadir, L.E. Nugroho, A. Y. Susanto, P. I. Santosa, "Experiments of zernike moments for leaf identification", Journal of Theoretical and Applied Information Technology, vol.41(1), pp. 82-93, 2012.

[178]J. S. Cope, D. Corney, J. Y. Clark, P. Remagnino, and P. Wilkin, "Plant species identification using digital morphometrics: A review," Expert Systems with Applications, vol. 39, no. 8, pp. 7562-7573, 2012.

[179] A. R. Backes and O. M. Bruno, "Plant leaf identification using color and multi-scale fractal dimension, "Computer Science, vol. 6134, pp. 463$470,2010$.

[180]J. Chaki, R. Parekh, and S. Bhattacharya, "Plant leaf recognition using texture and shape features with neural classifiers," Pattern Recognition Letters, vol. 58, pp. 61-68, 2015.

[181]Y. Naresh and H. Nagendraswamy, "Classification of medicinal plants: An approach using modified LBP with symbolic representation," Neurocomputing, vol. 173, pp. 1789-1797, 2016.

[182]G. L. Grinblat, L. C. Uzal, M. G. Larese, and P. M. Granitto, "Deep learning for plant identification using vein morphological patterns," Computers and Electronics in Agriculture, vol. 127, pp. 418-424, 2016. 


\section{International Journal of Innovative Research in Electrical, Electronics, Instrumentation and Control Engineering}

Vol. 6, Issue 8, August 2018

[183]C. Zhao, S. S. Chan, W.-K. Cham, and L. Chu, "Plant identification using leaf shapes-A pattern counting approach," Pattern Recognition, vol. 48, no. 10, pp. 3203-3215, 2015.

[184]B.S. Bama, S.M. Valli, S. Raju, and V.A. Kumar, "Content based leaf image retrieval (cblir) using shape, color and texture features," Indian Journal of Computer Science and Engineering, p. 202211, 2011.

[185]V. Satti, A. Y. Satya, S. Sharma, "An automatic leaf recognition system for plant identification using machine vision technology", International Journal of Engineering Science and Technology, vol . 5(4), pp.: 874-879, 2013.

[186]S. Zhang, Y.K. Lei, "Modified locally linear discriminant embedding for plant leaf recognition" In: Elsevier: Neurocomputing, 74 (14), pp. 2284-2290, 2011.

[187]J. Hossain, M.A. Amin, "Leaf shape identification based plant biometrics", In: Institute of Electrical and Electronics Engineering (IEEE), Proceedings of 13th International Conference on Computer and Information Technology, pp. 458-463, 2010.

[188]C. Uluturk and A. Ugur, "Recognition of leaves based on morphological features derived from two half-regions," 2012 International Symposium on Innovations in Intelligent Systems and Applications, 2012.

[189] A. H. M. Amin and A. I. Khan, "One-shot Classification of 2-D Leaf Shapes Using Distributed Hierarchical Graph Neuron (DHGN) Scheme with k-NN Classifier," Procedia Computer Science, vol. 24, pp. 84-96, 2013.

[190]M. G. Larese, R. Namías, R. M. Craviotto, M. R. Arango, C. Gallo, and P. M. Granitto, "Automatic classification of legumes using leaf vein image features," Pattern Recognition, vol. 47, no. 1, pp. 158-168, 2014.

[191]X. Wang, B. Feng, X. Bai, W. Liu, and L. J. Latecki, "Bag of contour fragments for robust shape classification," Pattern Recognition, vol. 47, no. 6, pp. 2116-2125, 2014

[192]C. H.arun, W. R. S. Emmanuel, and D. C. Durairaj, "Texture Feature Extraction for Identification of Medicinal Plants and comparison of different classifiers," International Journal of Computer Applications, vol. 62, no. 12, pp. 1-9, 2013

[193]B. Fataniya, T. Zaveri, and S. Acharya, "Classification of Microscopic Image of Herbal Plants from Its Powder Using Speeded-Up Robust Features,” Journal of Advanced Microscopy Research, vol. 13, no. 3, pp. 326-332, Jan. 2018. 